\title{
Stochastic modelling of beach profiles including the influence of thickener performance
}

\author{
KD Seddon ATC Williams Pty Ltd, Australia \\ B Pirouz ATC Williams Pty Ltd, Australia \\ S Javadi ATC Williams Pty Ltd, Australia
}

\begin{abstract}
It is generally well accepted that in the design and operation of thickened tailings storages, 'better' thickener performance will improve the beach profile, and thereby enhance the overall performance of the stack. Conversely, if the thickener does not perform well, it is unlikely that the designed beach profile will be achieved.

The aim of this paper is to demonstrate quantitatively how thickener performance can influence the achieved beach profile in a thickened tailings scheme.

The two contributing factors are: (i) solids concentration (as a surrogate for actual rheology), and (ii) throughput or flow rate. There are two considerations for each influencing factor. For solids concentration, these are: (i) does the thickener achieve the design target value, and (ii) what is the variability around this value. For flow rate, these are: (i) is the plant running at, above or below the design throughput, and (ii) what is the variability around this value.

This paper presents an extension of previous work by the authors on the subject of stochastic beach profile prediction. Seddon et al. (2015) showed that the statistical variability of thickener underflow (in terms of flow rate and solids concentration) could be used in an incremental deposition model to predict realistic beach profiles. Additional statistics of actual thickener performance were presented by Pirouz et al. (2017).

This paper uses a previously generated profile (Seddon et al. 2015) as a starting point, and investigates the influence of: (i) increased variability in performance (resulting in greater concavity in the profile), and (ii) an overall reduction in achieved underflow solids concentration combined with an increase in throughput (together resulting in greater concavity and an overall flatter profile).
\end{abstract}

Keywords: thickened tailings, beach profile, beach slope, stochastic modelling, thickeners

\section{Introduction}

One of the central concepts of the thickened discharge system is that discharge of thickened, non-segregating tailings will result in a consistent beach slope. The implication is that for a constant flow rate and slurry density (or strictly, for constant slurry rheology), tailings will form a uniform planar beach slope down the full length of the beach.

In practice, beach profiles with a greater or lesser degree of concavity are commonly encountered for thickened and paste tailings beaches.

Seddon and Fitton (2011) proposed that concave beach profiles can be attributed to the fact that tailings rheology and discharge rates do not stay constant over a period of time. Data demonstrating that the variable throughput of thickeners can be characterised on a statistical basis was also presented.

Seddon et al. (2015) then presented a more rigorous design methodology utilising a stochastic approach to predict beach slope as a time series, and to model the subsequent build-up of the beach using a short time step increment as input into a tailings deposition type program. 
The aim of the 2015 paper was to demonstrate that realistic beach slope profiles (concavity) could be generated if the observed variability of thickener performance was included in the analysis. As such, only a single beach profile was modelled.

The aim of this present paper is to investigate the possible variability of beach profiles, both in terms of concavity and overall slope, if the statistical parameters of thickener performance are varied.

\section{Background}

\section{$2.1 \quad$ Overview}

On the basis of observations of collected data on thickeners, Seddon and Fitton (2011) proposed that thickener performance could be evaluated on a statistical basis. The two variables that were investigated were solids concentration and mass flux; these being the values most commonly recorded during operations. At that time, the majority of the data was in a daily format, and was analysed on this basis. It is recognised that daily sampling (as in some form of daily mean value for solids concentration, and total daily throughput to calculate flow rate) almost certainly results in an underestimate of overall variability. It seems that with increased levels of instrumentation and automation, data at more frequent intervals is now available at some sites, and is expected to provide better design parameters in due course. However, for the purpose of this paper, the use of daily inputs has been retained, as to date most of the analysis of variation has been on this basis.

Seddon and Fitton (2011) characterised thickener performance in terms of statistical normal distributions, formulated in terms of a mean and a standard deviation. For comparing the spread or variability over different distributions, the coefficient of variability (CV) was used, where CV = standard deviation/mean.

The normal distribution curves presented by Seddon and Fitton (2011) provided a reasonable fit for solids concentration, but is was recognised that the data for (mass) flow rate of solids was asymmetrical, and the normal distribution did not provide a particularly good fit. The further analysis of subsequent datasets has supported this (Pirouz et al. 2017). It would be possible to fit a different mathematical distribution to these data. However, for present purposes, an approach based on a 'two-tailed' normal distribution has been adopted. This uses the same mean value for the upper and lower distributions, but a larger standard deviation for the more skewed lower data.

\subsection{Solids concentration}

For the variability of underflow solids concentration, Seddon and Fitton (2011) reported values of CV in the range of $0.025-0.08$. Seddon et al. (2015) adopted a value of 0.05 in their reported analysis. Incorporation of the additional thickener data (Pirouz et al. 2017) has not changed this assessment, which is still considered to be a reasonable estimate for a well operated thickener.

\subsection{Mass flow rate}

For characterisation of mass flow rate, Seddon and Fitton (2011) reported values of CV in the range of $0.12-0.19$, noting that this was based on the use of a symmetrical distribution.

Seddon et al. (2015) adopted an asymmetrical distribution using CV $=0.07$ for the top, and CV $=0.12$ for the bottom of the range. This is still considered to be representative of 'good' thickener operations (Pirouz et al. 2017).

\section{$3 \quad$ Methodology}

As noted above, the commonly available data on thickener performance are solids concentration and mass flux. For the purposes of beach slope prediction, it is necessary to convert these values to representative rheological parameters and volumetric flux (Seddon et al. 2015). The methodology adopted in this paper to 
predict beach profiles is a replication of that set out in Seddon et al. (2015). The basic steps in the process are as follows:

- Establish or select statistical parameters for solids concentration and throughput (mass flux).

- Convert solids concentration to equivalent slurry rheology.

- Calculate volumetric flow rate for the applicable range of combinations of mass throughput and solids concentration.

- Select an appropriate method of beach slope prediction, and calculate the beach slope for each combination of flow and rheology, hence develop a predictive (cumulative) frequency curve for beach slope.

- Using deposition software, in this case Muck3D (MineBridge 2017), model the build-up of the beach in a step-wise manner.

In this paper (as in Seddon et al. 2015), beach slope predictions have been carried out using the method of Pirouz et al. (2014), although other equivalent methods could be used.

Finally, it should be noted that the method used herein assumes that the underflow solids concentration is independent of the mass flow rate. This has been checked for some, but not all, of the available datasets, and shown to be a reasonable assumption (Pirouz et al. 2017).

\section{$4 \quad$ Cases modelled}

\subsection{Base Case}

The Base Case has been taken directly from the case modelled by Seddon et al. (2015). This is an artificial case, but the actual tailings parameters were taken from a set of real test results, and the overall modelled slopes are not unrepresentative of actual sites of similar size. The Base Case parameters are summarised in Table 1.

Table 1 Base Case conditions

\begin{tabular}{lll}
\hline Parameter & Unit & Quantity \\
\hline Nominal plant throughput & Mtpa (dry) & 10.0 \\
Annual operating time & $\mathrm{hrs}$ & 8,000 \\
Solids particle density (specific gravity) & $\mathrm{t} / \mathrm{m}^{3}$ & 2.65 \\
Underflow solids concentration* (Cw) & $\%$ & 66.0 \\
Coefficient of variation & - & 0.05 \\
Mass flux (mean) & $\mathrm{t} / \mathrm{hr}$ & 1,250 \\
Coefficient of variation (top) & - & 0.07 \\
Coefficient of variation (bottom) & - & 0.12 \\
For deposition modelling & & \\
Nominal daily throughput & $\mathrm{t} / \mathrm{day}$ & 30,000 \\
In situ density (dry), end of filling & $\mathrm{t} / \mathrm{m}^{3}$ & 1.50 \\
Nominal daily volume increment & $\mathrm{m}^{3}$ & 20,000 \\
\hline
\end{tabular}

*Value corresponding to the P85 point on the distribution curve. 
It should be noted that the design target value for underflow solids concentration of $66 \%$ relates to the P85 point on the distribution curve (Figure 1). The design target value for throughput is the mean point on the distribution curve (Figure 2).

\section{Solids Concentration}

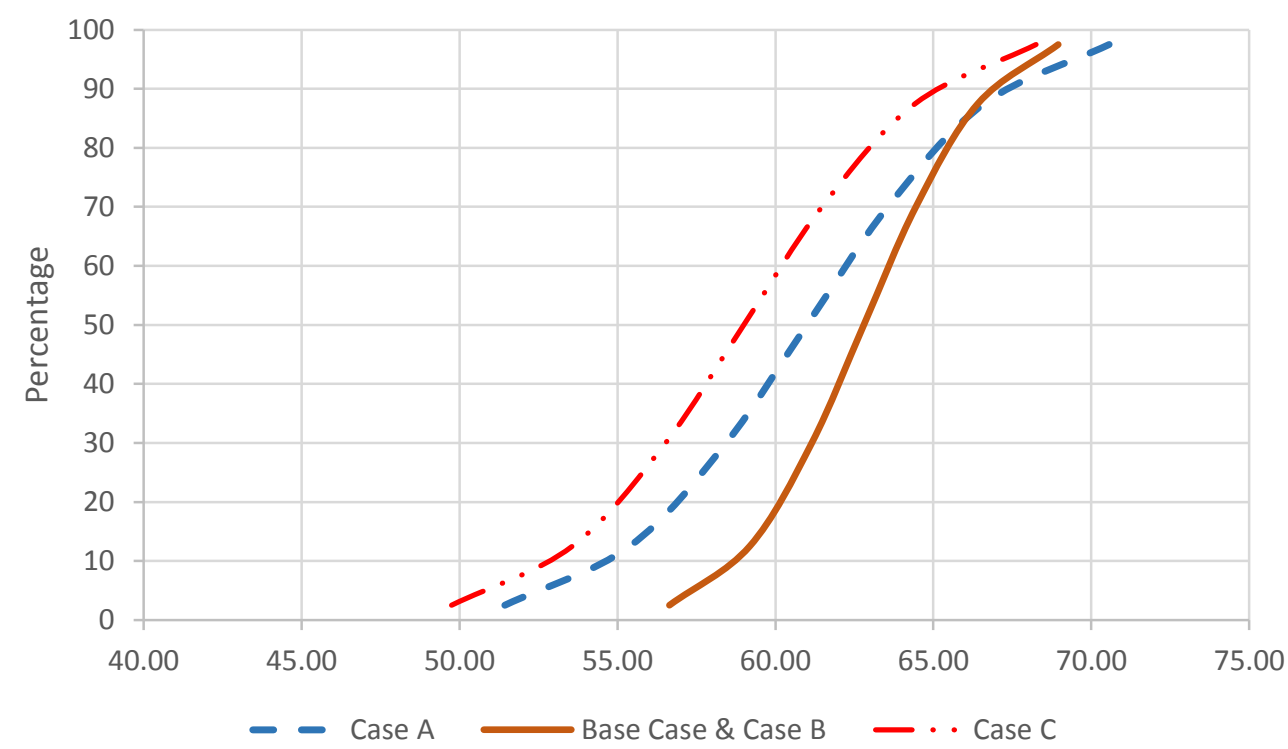

Figure 1 Cumulative frequency distributions for solids concentration

Throughput (Mtpa)

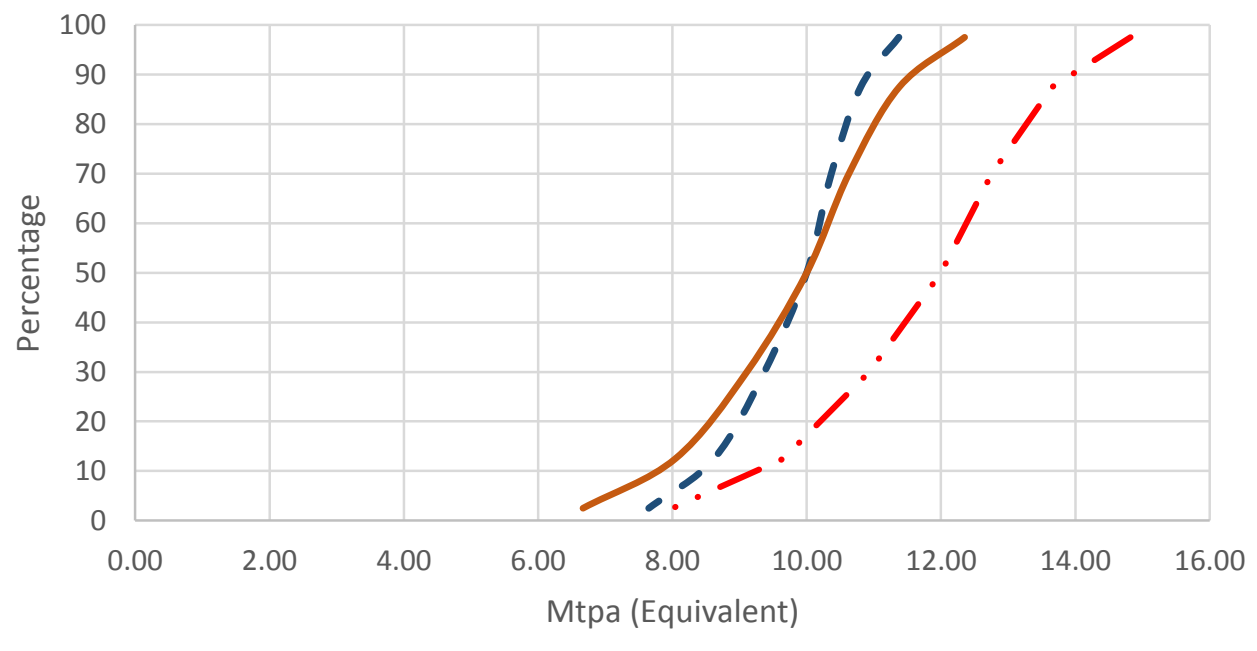

- Base Case \& Case A Case B — Case C

Figure 2 Cumulative frequency distributions for throughput 


\subsection{Additional cases}

Three additional cases have been considered in this paper to demonstrate the effects of:

- Increased variability of underflow solids concentration.

- Increased variability of throughput (mass flux).

- Changes in the set points for the distribution curves, plus increased variability.

The actual cases modelled are set out below, with the resulting cumulative distribution curves shown in Figure 1 (solids concentration) and Figure 2 (throughput).

Case A: The CV for the underflow solids concentration was increased to 0.08 (compared to 0.05 for the Base Case). In applying this, the design target value of $66 \%$ solids at P85 on the distribution curve has been retained. This results in a reduction in the mean value $(\mathrm{P} 85)$ by around $1.8 \%$ solids compared to the Base Case (Figure 1). The throughput assumptions were not changed from the Base Case.

Case B: The CV for the throughput (mass flux) was increased to 0.12 for the top half of the distribution, and to 0.17 for the bottom half (compared to 0.07 and 0.12 respectively for the Base Case). The assumptions relating to underflow solids concentration were not changed from the Base Case.

Case C: This case evaluates the impact of somewhat larger variations from the Base Case. In this case, the throughput has been increased by $20 \%$, to a mean value of $1,500 \mathrm{t} / \mathrm{hr}$ (12 Mtpa) compared to the 1,250 t/hr Base Case. This type of increase is not uncommon. In this example, it is modelled to occur without any corresponding increase in thickener size/capacity, and hence results in an increase in the unit flux through the thickener. For this reason, or other causes, the thickener is assumed to be no longer performing to the design value, and the P85 underflow solids concentration is reduced to $63.5 \%$, a reduction of $2.5 \%$ solids compared to the Base Case of $66 \%$ solids. Again, this magnitude in the shortfall on thickener performance is not unknown in practice. In addition to these changes, the greater variability of underflow solids concentration (as in Case A) and throughput (as Case B) are both retained.

It should be noted that both decreased solids concentration (rheology) and increased throughput (flow rate) act to decrease the resulting beach slope. Case $\mathrm{C}$ is therefore expected to return a significantly lower overall slope, with greater concavity, compared to the other cases.

\section{$5 \quad$ Beach slope variability}

The beach slope variability was calculated following the procedure of Seddon et al. (2015) as summarised previously. For each of the three new cases, the beach slope was calculated across the range of solids concentration and flow rate relevant to each case, using the method of Pirouz et al. (2014).

Reference to Figure 1 will indicate that it is necessary to model underflow solids concentration ranging from between 50 and $70 \%$. Similarly, Figure 2 indicates throughput ranging between the equivalents of $6 \mathrm{Mtpa}$ to close to $15 \mathrm{Mtpa}$.

The overall results of the calculation of beach slope as a function of solids concentration and flow rate are shown in Figure 3. The results indicate that under the conditions modelled, solids concentration has more influence on beach slope than flow rate.

The calculation also enables probability distribution curves of beach slope to be developed for each case. These results are shown in Figure 4, together with the Base Case curve.

The Base Case analysis returned a beach slope ranging between 0.5 and $2.5 \%$, with a mean of $1.1 \%$. The greater variability included in Case $A$ has increased this to a range of $0.4 \%$ to close to $3 \%$, with the mean reduced to less than $1 \%$. In short, increased variability has flattened the overall slope and increased the concavity. 


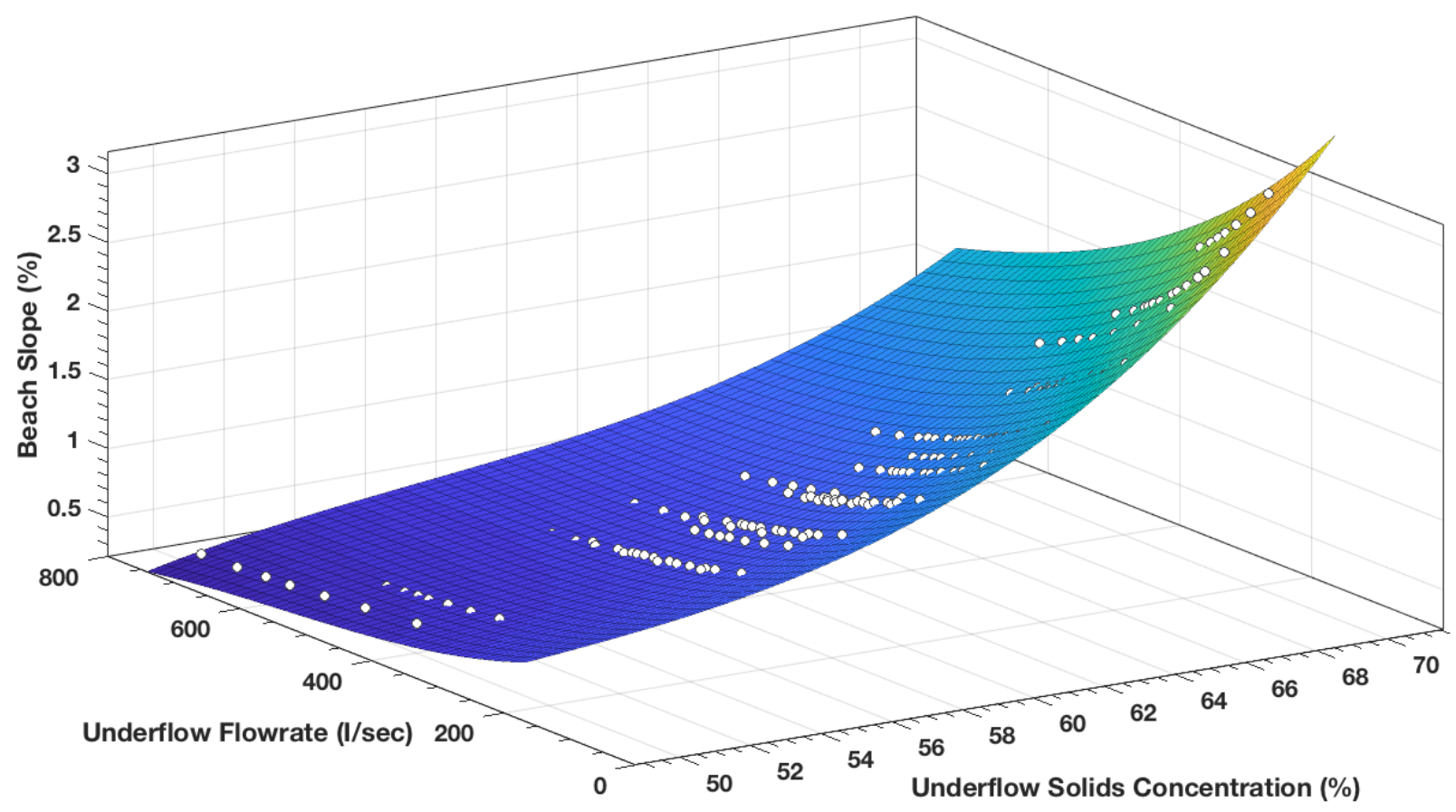

Figure 3 Beach slope dependence on solids concentration and flow rate

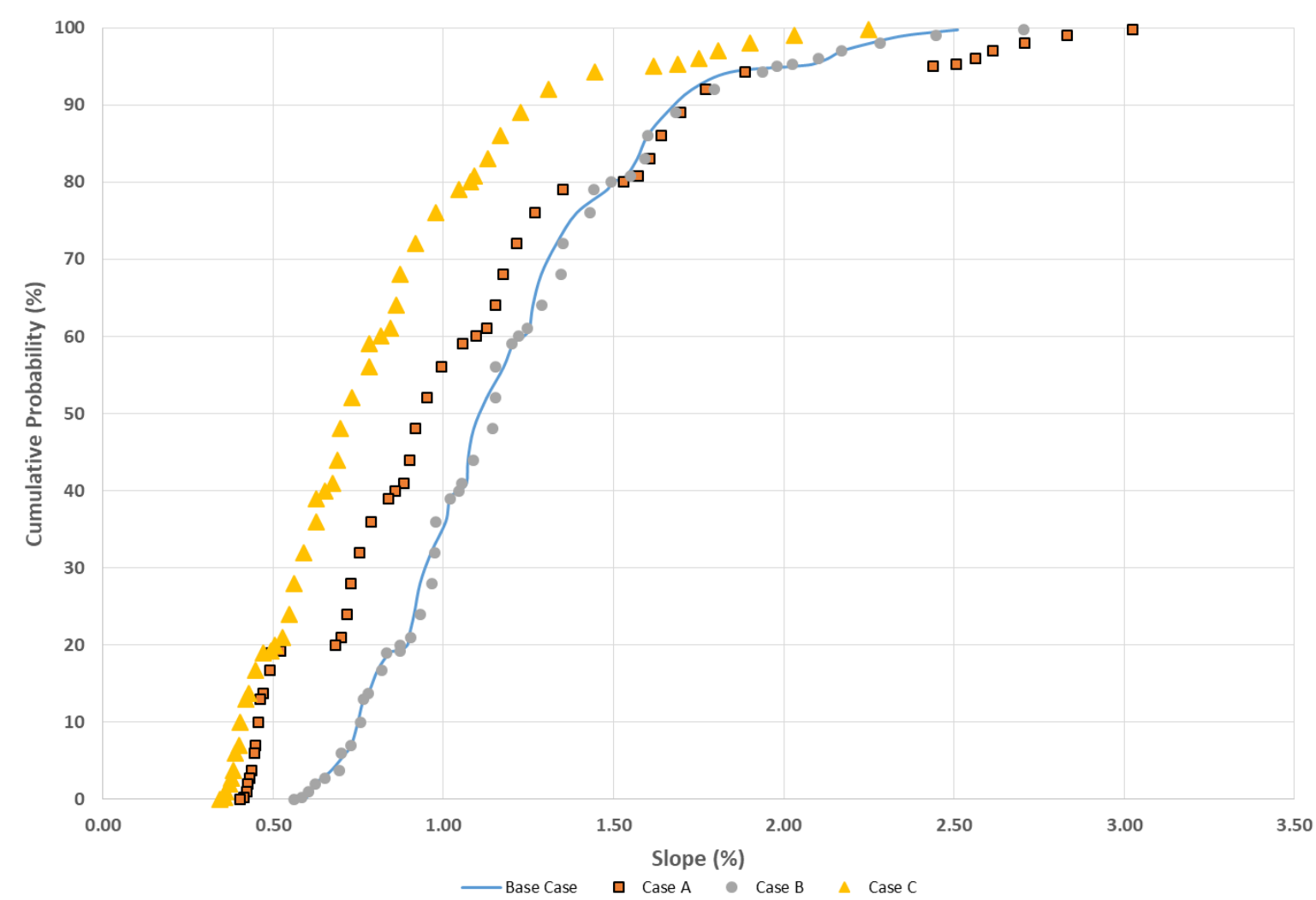

Figure 4 Derived cumulative beach slope frequency distribution

Interestingly, the trialled changes in Case B (increased variability of throughput) had little influence.

Case $\mathrm{C}$ returned a profile ranging from less than $0.4 \%$ to around $2.5 \%$, and a further reduced mean of $0.7 \%$. This value is only $63 \%$ of the design Base Case. 


\section{$6 \quad$ Modelled beach profiles}

To generate an actual profile, the beach for each case was modelled on a step-wise basis, using daily beach slope values as input to the MineBridge Muck software package.

The model was set up to run for a central thickened discharge (CTD) configuration, assuming a horizontal base plane, a single central discharge point, and a daily volumetric requirement of $20,000 \mathrm{~m}^{3} /$ day (Table 1). To limit modelling run-time, the deposition models were only run to simulate the first year of deposition. Because of the 3D nature of the modelled stack, it is considered that further modelling will result in some changes to the profile details. For design purposes, it is recommended that the model should be run to replicate the full life of the storage.

The results are shown in Figure 5, which for comparison also represents the profile modelled in the original Base Case. The curves shown are the averages of four profiles taken at right angles through the modelled surface. The results confirm the discussion in Section 5 based on the cumulative distribution curves.

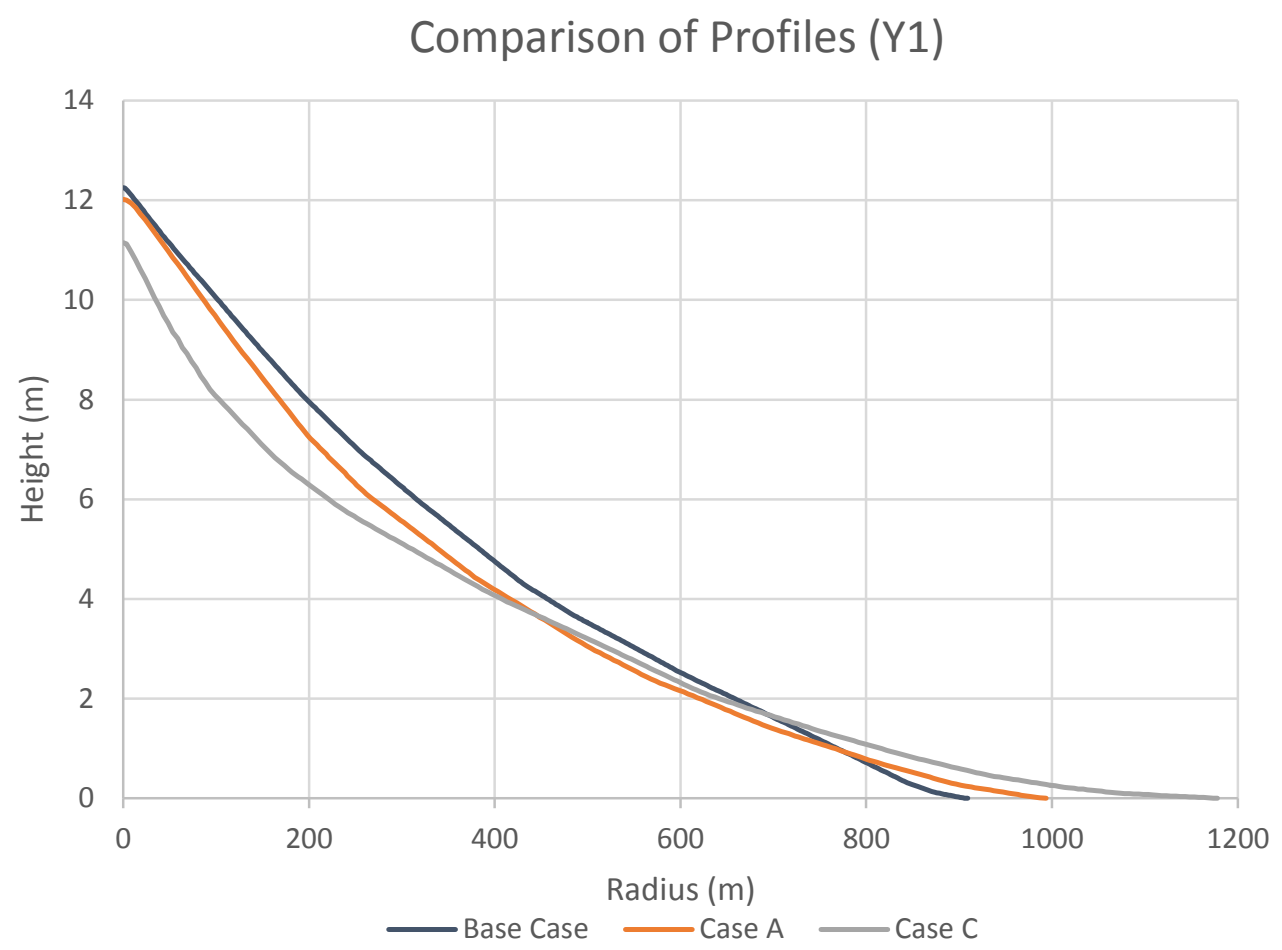

Figure 5 Comparison of derived beach profiles (at end of year one)

In viewing the profiles in Figure 5, it should be appreciated that these represent a 3D surface, and therefore the curves do not adequately reflect the true volumes of material accounted for under each of the different slope angles. This is illustrated in Figures 6(a), (b) and (c) which show the profile for each of the Base Case, Case $A$ and Case $C$ respectively, together with the equivalent angle of a uniform conical stack having the same radius and volume. These results are summarised in Table 2.

Table 2 Summary beach parameters (at end of year one)

\begin{tabular}{lllll}
\hline Parameter & Unit & Base Case & Case A & Case C \\
\hline Stack radius (approximate) & $\mathrm{m}$ & 900 & 1,000 & 1,100 \\
P50 slope (from Figure 4) & $\%$ & 1.1 & 0.93 & 0.71 \\
Equivalent uniform slope & $\%$ & 0.95 & 0.71 & 0.49 \\
\hline
\end{tabular}




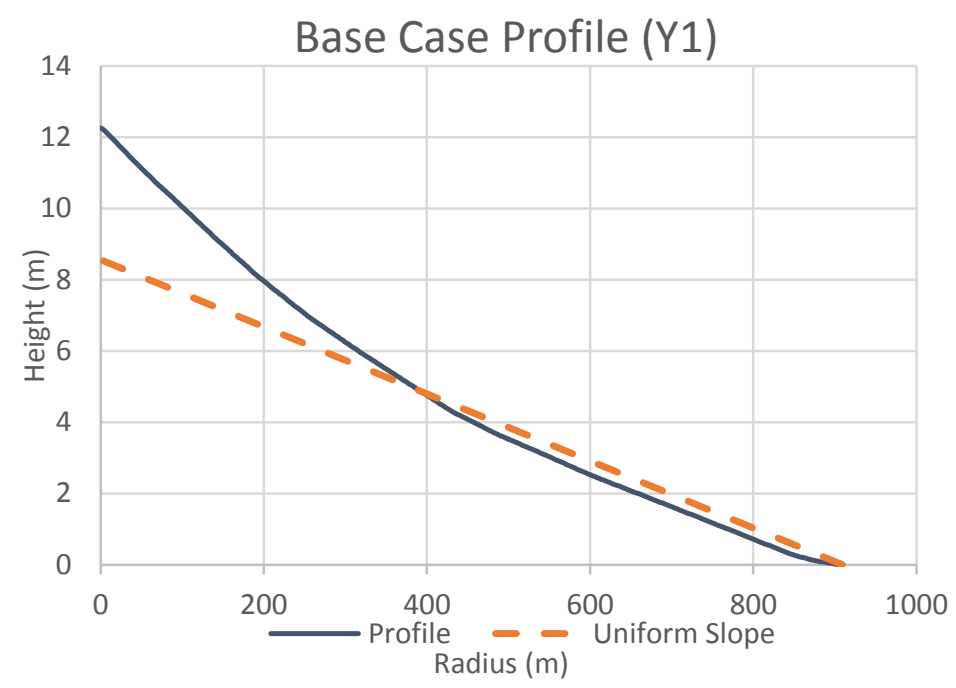

(a)

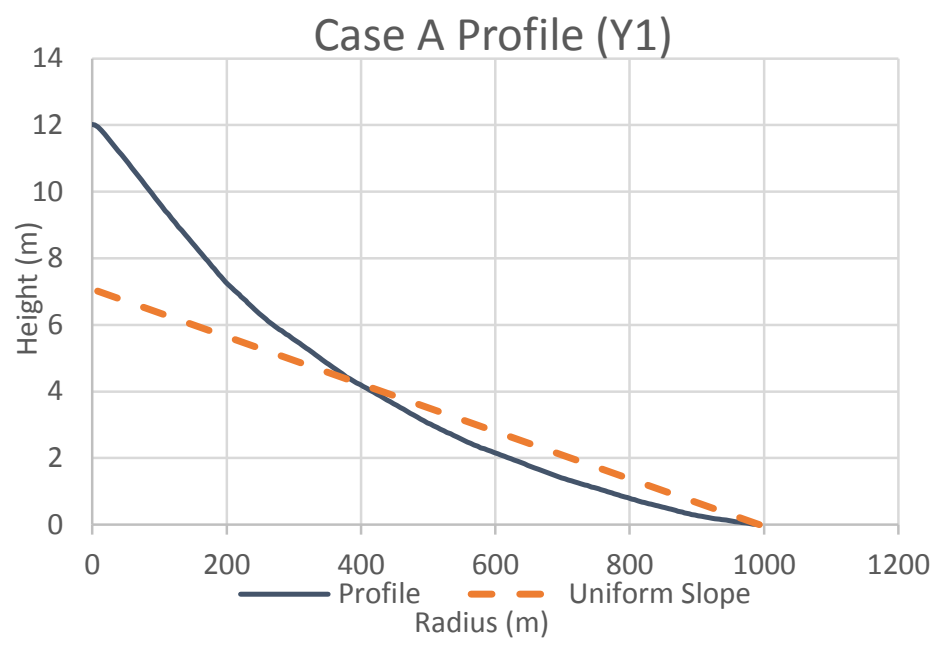

(b)

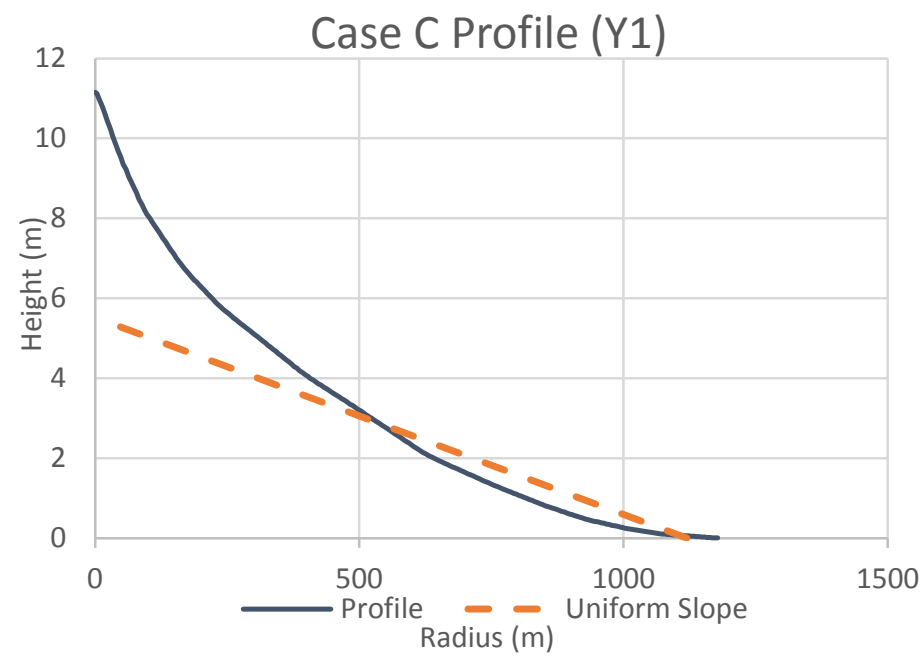

(c)

Figure 6 (a) Equivalent uniform beach slope: Base Case (and Case B); (b) Equivalent uniform beach slope: Case $A$; and, (c) Equivalent uniform beach slope: Case $C$ 


\section{Discussion/design implications}

The results presented in this paper have demonstrated that relatively small changes in operating parameters can significantly influence the obtained beach profile. This applies particularly to variations in solids concentration.

Larger deviations, such as a thickener failing to achieve the design solids concentration/rheology, have the potential to seriously disrupt the design and operation of a CTD beach.

For initial design studies, it may be useful to adopt a single representative beach slope (as shown in Figure 6). But it must be appreciated that to be realistic this needs to be something approaching the probabilistic P50 value (Figure 4). For detailed design, a full accounting for profile curvature should be undertaken. Any storage design which is based on a single uniform beach slope is delusional. It also follows from this that any beach slope design method that does not have the ability to capture the effects of thickener variability is less than useful.

Overall, it is recommended that at the design stage, a series of sensitivity analyses should be carried out to investigate the possible range of beach profiles that may be experienced in practice, and to plan to manage these. Wherever possible, contingencies for the worst case scenarios should be incorporated in the operational planning for the storage.

In particular during the commissioning and early operations phase it seems that thickeners quite often do not perform to full design expectations. In some operations, there is sufficient reserve storage/flexibility at this time to provide time for thickener operations to be improved, and/or to modify the storage design. In cases where this reserve capacity does not exist by virtue of the particular design, it is strongly recommended that the design layout or staging should be amended to provide this reserve capacity.

Further work on the statistics of thickener performance would be valuable. Collection of additional data, e.g. semi-continuous sampling of solids concentration and flow rate, and inline rheometer results, or at least rake torque and pipeline pressure differential as a measure of rheology, is encouraged.

Finally, these results have relevance to attempts to validate beach slope prediction methods by comparison with measured slopes from operating facilities. Statements such as "...we are advised that the thickener has been achieving an average solids content of $x \%$, and the average beach slope is estimated to be $y \% . . . "$ are common in the literature. These have their place, but it is suggested that data like this should not be used for detailed validation of beach slope prediction methods. At the least, a full beach profile should be provided, together with historical thickener performance data, for a duration as long as possible.

It is noted that some authors have suggested that beach slope methods are wrong (have room for improvement), based on the observation that, in many cases, the operating beach has failed to achieve the design value. This may well be the case, but the results in this paper suggest that the first step in evaluation of a beach profile that is not in accordance with design expectations should be to collect and check the thickener performance data, as well as validation of the rheology/solids concentration relationship of the tailings slurry.

\section{Conclusion}

Relatively small changes in thickener operating parameters can significantly influence the obtained beach profile. Larger deviations, such as a thickener failing to achieve the design solids concentration/rheology, have the potential to seriously disrupt the design and operation of a CTD scheme.

In the design phase of a thickened tailings facility, a risk/sensitivity analysis is recommended to evaluate the effect of possible variations.

\section{References}

MineBridge Software, 2017 Muck3D Tailings, http://www.minebridgesoftware.com/products/muck3d-tailings/ 
Pirouz, B, Javadi, S, Seddon, KD \& Williams, MPA 2014, 'Modified beach slope prediction model for non-segregating tailings', in RJ Jewell, AB Fourie, PS Wells and D van Zyl (eds), Proceedings of the 17th International Seminar on Paste and Thickened Tailings, InfoMine Inc., Vancouver, pp. 31-45.

Pirouz, B, Javadi, S \& Seddon, KD 2017, 'Thickener performance variability: underflow solids concentration and flowrate', in A Wu and RJ Jewell (eds), Proceedings of the 20th International Seminar on Paste and Thickened Tailings, University of Science and Technology Beijing, Beijing, pp. 10-11.

Seddon, KD \& Fitton, TG 2011 'Realistic beach slope prediction and design', in RJ Jewell and AB Fourie (eds), Proceedings of the 14th International Seminar on Paste and Thickened Tailings, Australian Centre for Geomechanics, Perth, pp. 281-293

Seddon, KD, Pirouz, B \& Fitton, TG 2015, 'Stochastic beach slope modelling', in RJ Jewell and AB Fourie (eds), Proceedings of the 18th International Seminar on Paste and Thickened Tailings, Australian Centre for Geomechanics, Perth, pp. 455-465. 